\title{
Prenatal Stress Exposure Increases the Excitation of Dopamine Neurons in the Ventral Tegmental Area and Alters Their Reponses to Psychostimulants
}

\author{
Kathryn Hausknecht', Samir Haj-Dahmane' and Roh-Yu Shen*, \\ 'Research Institute on Addictions, University at Buffalo, Buffalo, NY, USA
}

\begin{abstract}
Prenatal stress exposure (PSE) is known to increase addiction risk. Dopamine (DA) neurons in the ventral tegmental area (VTA) play an important role in addiction. In order to understand the cellular mechanisms underlying PSE-induced increase in addiction risk, we examined the effects of PSE on the electrical impulse activity of VTA DA neurons using the in vivo extracellular single-unit recording technique. Amphetamine self-administration was also conducted to confirm increased addiction risk after PSE. The PSE was carried out by restraining pregnant dams from GD II to 20. Adult male offspring (3-6 months old) were used in the experiments. Animals with PSE showed enhanced amphetamine self-administration compared with controls when amphetamine dose was reduced after acquisition. The number of spontaneously active VTA DA neurons was also reduced in PSE rats. The reduction was reversed by acute apomorphine that normally inhibits the impulse activity of DA neurons. The reversal effect suggests that PSE-induced reduction in the number of spontaneously active VTA DA neurons is caused by overexcitation to the extent of depolarization block. Furthermore, the reduced number of spontaneously active VTA DA neurons was also reversed by acute psychostimulants (eg, amphetamine; cocaine), which in control rats inhibited the activity of VTA DA neurons. The reversal effect on VTA DA neuron in PSE animals represents an actual increase in the impulse activity. This effect might contribute to increased responding to psychostimulants and mediate increased addiction risk after PSE.

Neuropsychopharmacology (2013) 38, 293-30I; doi:I0.1038/npp.2012.168; published online 5 September 2012
\end{abstract}

Keywords: depolarization block; self-administration; amphetamine; cocaine; addiction risk

\section{INTRODUCTION}

There are individual differences in the risk for developing drug addiction. Only a proportion of individuals develop drug addiction after using drugs repeatedly (Everitt et al, 2008). Ample evidence from clinical studies show that stress during the perinatal period (prenatal and early postnatal) in the form of mental or physical stress could lead to increased addiction risk during adulthood (Charmandari et al, 2003). Results from animal studies also show that perinatal stress leads to behavioral phenotypes associated with increased addiction risk including increased locomotor activity to novelty (Piazza et al, 1989), anxiety/depression-like behaviors, impulsivity, enhanced hypothalamic-pituitaryadrenal (HPA) axis reactivity, and locomotor sensitization to psychostimulants (Deminiere et al, 1992; Maccari and Morley-Fletcher, 2007; Marinelli and Piazza, 2002). Perinatal stress also directly leads to increased addiction risk demonstrated by enhanced acquisition (Deminiere et al,

*Correspondence: Dr R-Y Shen, Research Institute on Addictions, University at Buffalo, 1021 Main Street, Buffalo, NY 14203, USA, Tel: + I 716887 2593, Fax: + I 716887 2476, E-mail: shen@ria.buffalo.edu. Received 4 April 2012; revised 31 July 2012; accepted I August 2012
1992; Thomas et al, 2009), greater resistance to extinction training, and enhanced drug-induced reinstatement in the psychostimulant self-administration paradigm (Kippin et al, 2008).

Despite strong evidence linking perinatal stress with increased addiction risk, the cellular mechanisms mediating this effect are not well understood. Results from previous animal studies show that adaptational changes in the mesolimbic/cortical dopamine (DA) systems, which are the major targets for drugs of abuse (Koob and Le Moal, 1997), could play a critical role in addiction. Specifically, the changes in DA neuron cell body areas located in the ventral tegmental area (VTA) are important in mediating addiction or increased addiction risk. For example, intra-VTA administration of psychostimulants enhances the subsequent cocaine self-administration (Suto et al, 2003) and reinstates drug-seeking behavior (Shaham et al, 2003). In addition, numerous studies report increased glutamate synaptic transmission in VTA DA neurons after psychostimulant, ethanol, or stress exposure, the conditions known to increase addiction risk (Borgland et al, 2004; Fitzgerald et al, 1996; Ortiz et al, 1995; Saal et al, 2003; Ungless et al, 2001; White et al., 1995; Zhang et al, 1997). Directly enhancing and blocking glutamate receptor expression in 
VTA DA neurons lead to increased responding to drug reward (Carlezon et al, 2000), and prevent enhanced psychostimulant self-administration (Suto et al, 2003), respectively.

Consistent with the finding that increased glutamate neurotransmission in VTA DA neurons is an important cellular mechanism for increased addiction risk, exposure to psychostimulants or ethanol leads to persistent overexcitation in VTA DA neurons recorded in vivo, presumably to the degree of depolarization block (Shen and Choong, 2006; Shen et al, 2007) and enhanced sensitivity to psychostimulants (Xu and Shen, 2001). These findings suggest that overexcitation of VTA DA neurons could contribute to increased addiction risk after perinatal stress exposure. In this study, we investigated this possibility by examining the impact of prenatal stress exposure (PSE) on the spontaneous electrical impulse activity of VTA DA neurons and their responses to psychostimulants. The amphetamine self-administration procedure was also used to verify that the PSE paradigm could indeed lead to increased addiction risk.

\section{MATERIALS AND METHODS}

\section{Subjects and PSE Procedures}

All procedures involving animals were in accordance with the National Institutes of Health and American Association for Accreditation of Laboratory Animal Care guidelines, and approved by the University at Buffalo Institutional Animal Care and Use Committee. Adult male (300-450 g) and virgin female (225-250 g) Sprague-Dawley rats were housed together under a 12/12 light/dark cycle until vaginal plugs were found $(<10$ days). Pregnant dams were randomly assigned to the control or PSE group and housed two per cage until gestational day (GD) 20. Afterward, dams were single housed. Each dam in the PSE group was restrained in a rodent restrainer (IITC Life Science, Woodland Hills, CA) for $45 \mathrm{~min}, 3$ times/day under a bright light (6500 lux) from GD 11 to 20 (Maccari et al, 2003). Pups were culled to 8 on postnatal day 1 (PD1). Control dams received no treatment or handling except regular cage cleaning. Male offspring between 2 and 5 months of age were used. Locomotor activities were measured in locomotor chambers for $1 \mathrm{~h}$ in 7-week-old rats.

\section{Jugular Vein Surgery}

Rats were anesthetized with ketamine/xylazine $(65 \mathrm{mg} / \mathrm{kg}$ and $15 \mathrm{mg} / \mathrm{kg}$; i.p.). The external jugular vein was implanted with a heparinized cannula (Instech, Plymouth Meeting, PA) connected to an injection port in a harness (Instech). Rats were allowed to recover for at least 5 days after surgery. The catheters were flushed daily with 0.1 to $0.2 \mathrm{ml}$ solution of enrofloxacin $(4 \mathrm{mg} / \mathrm{ml})$ and heparinized saline $(50 \mathrm{IU} / \mathrm{ml})$ to preserve catheter patency.

\section{Electrophysiology}

The in vivo extracellular single-unit recordings were conducted under ketamine $(20 \mathrm{mg} / \mathrm{kg} ;$ i.p.) and urethane (15 min after ketamine; $1.0-1.5 \mathrm{~g} / \mathrm{kg}$; i.p.) anesthesia
(Brischoux et al, 2009). The skull and dura over the VTA were removed. The tail vein was cannulated in some rats for intravenous drug administration. Body temperature was monitored and maintained between $36.5^{\circ} \mathrm{C}$ and $37.5^{\circ} \mathrm{C}$. Heart rate and blood oxygen saturation were monitored. Recordings were limited to rats with heart rate between 280 and 400 beats/min and blood oxygen above $90 \%$. The attrition rate was $<5 \%$.

Recordings were carried out with glass micropipettes (1.5 mm o.d.; World Precision Instruments, Sarasota, FL) filled with $2 \mathrm{M}$ sodium chloride (impedance: 2 to $4 \mathrm{M}$ at $135 \mathrm{~Hz}$ ). DA neurons were identified by characteristics previously described (positive-negative waveform, wide action potential duration, slow firing rate, and irregular or burst firing pattern) (Grace and Bunney, 1983). The cellsper-track technique was performed to sample the number of spontaneously active VTA DA neurons per electrode track (population activity), firing rate, and burst firing pattern (Bunney and Grace, 1978). The recording electrode was passed through a stereotaxically defined block in the VTA (coordinates in $\mathrm{mm}$ : 2.8-3.4 anterior to interaural line; 0.6-1.0 lateral; $6.5-8.5 \mathrm{~mm}$ below the brain surface) systematically 12 times. The distance between tracks was $200 \mu \mathrm{M}$. The spontaneous electrical impulse activity from each DA neuron was recorded for 2-5 min online using the Datawave Sciwork software (Datawave Technologies, Loveland, CO). Mean firing rate of DA neurons was determined from DA neurons pooled within each group. Burst firing pattern was obtained from 300 to 500 spikes in each VTA DA neuron by analysis of interspike intervals. The onset and termination of a burst were defined by an interspike interval of $<80 \mathrm{~ms}$ and $>160 \mathrm{~ms}$, respectively (Grace and Bunney, 1984). Doublets were excluded in this study. The following parameters were used: burst number (percentage of total spikes within bursts), burst length (mean number of spikes within each burst), and percentages of burst cells (neuron with a burst number $>10 \%$ ) per group (Shen et al, 1994).

Pharmacological challenges were used to examine the potential mechanisms underlying changes in the activity of VTA DA neurons (see Shen and Choong, 2006) for detailed rationale). Recording was first performed on one side of VTA (randomly assigned) to establish the basal activity. At $20 \mathrm{~min}$ after the pharmacological challenge $(20 \mu \mathrm{g} / \mathrm{kg}$ apomorphine, $0.3 \mathrm{mg} / \mathrm{kg}$ amphetamine, or $5 \mathrm{mg} / \mathrm{kg}$ cocaine; i.v.; Sigma, St Louise, MO), the recording procedure was repeated on the second side of VTA.

\section{Amphetamine Self-Administration}

After 2 days of habituation ( $1 \mathrm{~h} /$ day) in the operant chambers, rats were trained to nose poke to acquire i.v. amphetamine infusions $(0.1 \mathrm{mg} / \mathrm{kg} /$ infusion $)$ on a fixed ratio (FR) 1 schedule for $2 \mathrm{~h}$. Each infusion was delivered over 5-7 s with a maximum fluid volume of $0.12 \mathrm{ml} /$ infusion. A maximum of 20 infusions/day was allowed. After rats acquired the FR 1 schedule (acquisition criterion: 17 infusions for 2 consecutive days), they were trained on the FR 2 schedule followed by the FR 3 schedule. Then, the amphetamine dose/infusion was decreased to $0.033 \mathrm{mg} / \mathrm{kg}$ for 3 days followed by $0.011 \mathrm{mg} / \mathrm{kg}$ for 3 days and $0.000 \mathrm{mg} /$ $\mathrm{kg}$ for 3 days on the FR 3 schedule. The maximal number of infusions for $0.033,0.011$, and $0.000 \mathrm{mg} / \mathrm{kg}$ amphetamine 
was 40 . Data analysis was conducted only in rats with patent cannula at the end of the self-administration experiments.

\section{Data Analysis}

The group comparisons for electrophysiological or selfadministration data were made by one-way or two-way analysis of variances (ANOVA) followed by Fisher's least significance difference (LSD) post hoc comparison test (Statistica Software, Tulsa, OK). When there were multiple dependent variables (such as pup numbers in each gender), multivariate analysis of variances (MANOVA) was used. Independent $t$-test was used for two-group comparisons. Pearson's product-moment correlation was used to compute the correlation coefficients and Fisher's ' $r$-to- $z$ ' transformation and $z$-test were used to test the differences among the correlation coefficients between firing rate and burst number. The $\chi^{2}$ test was used to analyze differences in the percent of bursting cells.

\section{RESULTS}

\section{Birth Outcome}

A total of 48 dams were used in this study. Parturition rate did not differ in the control $(18 / 20 ; 90 \%)$ and the PSE (20/ $28 ; 71 \%)$ dams ( $\chi^{2}$ test). One litter from the control and three litters from the PSE group had litter size $<8$. These litters were not used. There were no differences in overall litter size or litter size by gender (MANOVA, Figure 1a). There was a difference in pup weight on PD1. Univariate ANOVA followed by MANOVA (Wilks' $\lambda=0.61 ; \mathrm{F}_{3,30}=$ 6.40, $P<0.01)$ revealed that differences were in average pup weight/litter (control: $6.74 \pm 0.14 \mathrm{~g}$; PSE: $6.17 \pm 0.11 \mathrm{~g}$; $P<0.01$; Figure 1b), average male pup weight/litter (male control: $6.89 \pm 0.15 \mathrm{~g}$; male PSE: $6.25 \pm 0.12 \mathrm{~g} ; \quad P<0.01$; Figure 1b), and female pup weight/litter (female control: $6.55 \pm 0.15$ g; female PSE: $6.10 \pm 0.11 \mathrm{~g} ; P<0.05$; Figure $1 \mathrm{~b}$ ). These results are similar to that described by others using the same PSE paradigm (Lesage et al, 2004). There were no differences in adult weight in rats used in the electrophysiological experiments from PD60-150 between the control and PSE groups (Figure 1c). Consistent with the phenotype of increased addiction risk, the PSE animals exhibited higher locomotor activity in a novel environment ( $t$-test, $t_{38}=2.21, P<0.05$; Figure $1 \mathrm{~d}$ ).

\section{Prenatal Stress Exposure Increased the Responding to Amphetamine in the Self-Administration Experiment}

The results from the amphetamine self-administration experiment show that PSE did not affect amphetamine self-administration during acquisition when the dose was $0.1 \mathrm{mg} / \mathrm{kg} /$ infusion in active responses, infusions, or days to criterion (Control: $7.7 \pm 0.4$; PSE: $7 \pm 0.4$ days; Figure $2 \mathrm{a}$ and $b$ ). There were also no differences in these parameters between the control and PSE groups on the FR 2 or FR 3 schedule (Figure 2c). After amphetamine dose was reduced
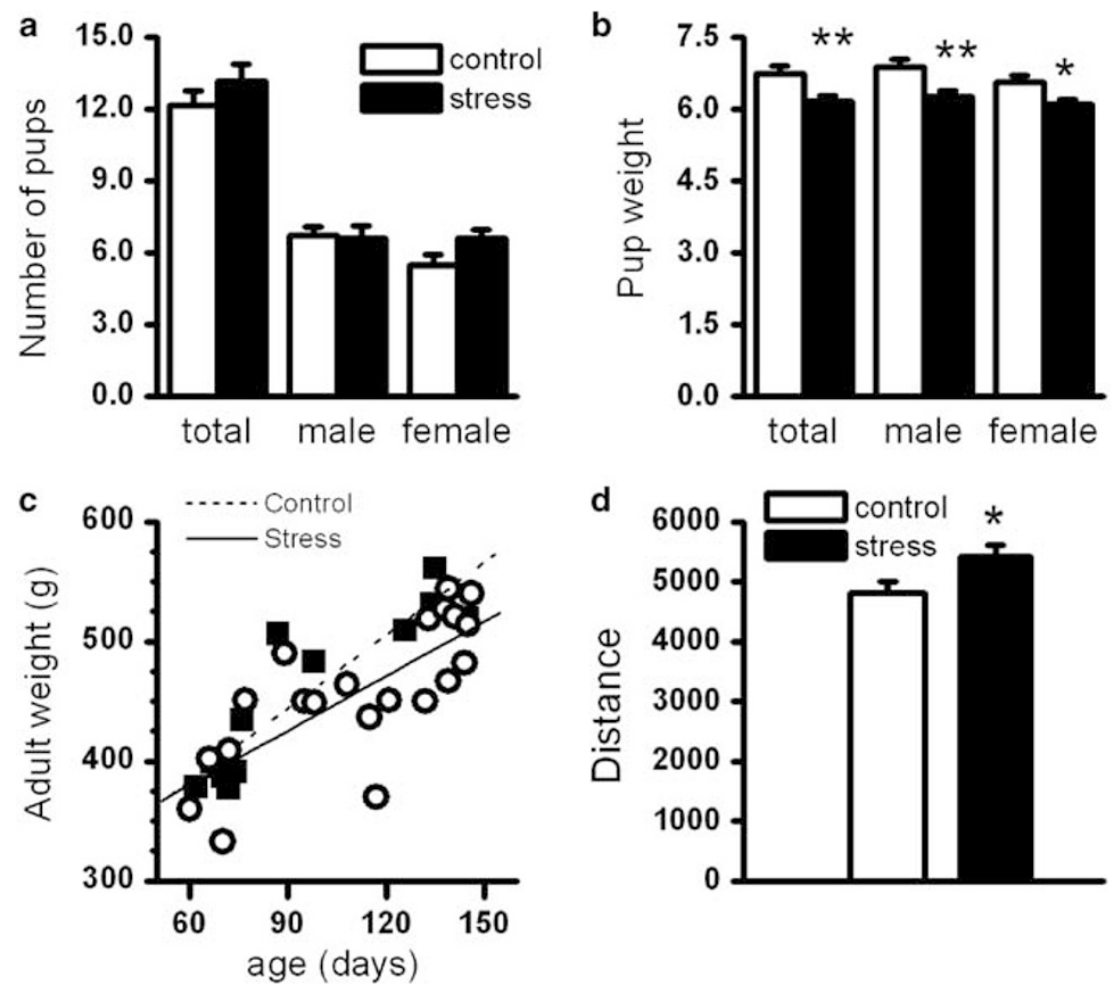

Figure I Birth outcomes after PSE by restraint. (a) The litter size did not differ between the control and PSE animals. (b) The mean birth bodyweight was significantly lower in pups with PSE than in control animals. The lower pup weight was reflected in both genders. The birth weight was measured on postnatal day I. (c) The adult body weight did not significantly differ in control and PSE animals. The correlation coefficients between age and bodyweight did not differ between control and PSE animals. (d) The locomotor activity in response to novelty (I h measurement) was significantly higher in the adult rats with PSE than in control rats. $* P<0.05 ; * * P<0.0$ I. 

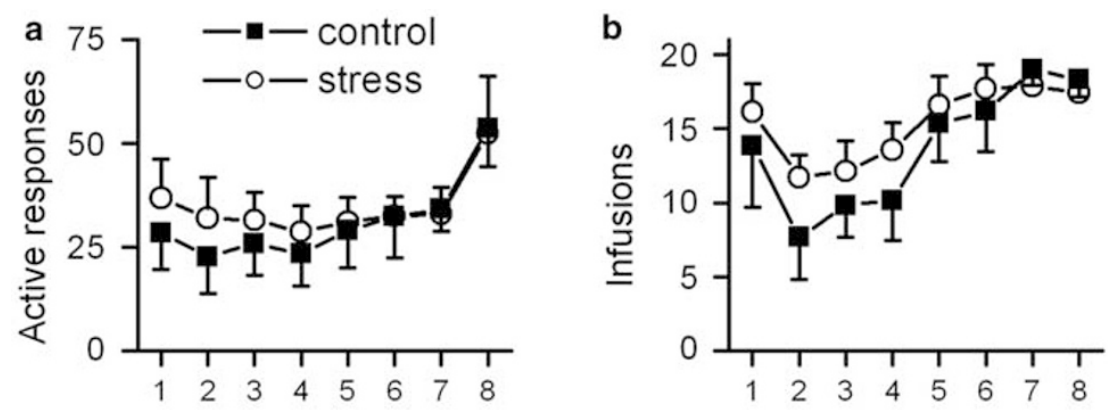

Acquisition session / $0.10 \mathrm{mg} / \mathrm{kg} / \mathrm{inf}$
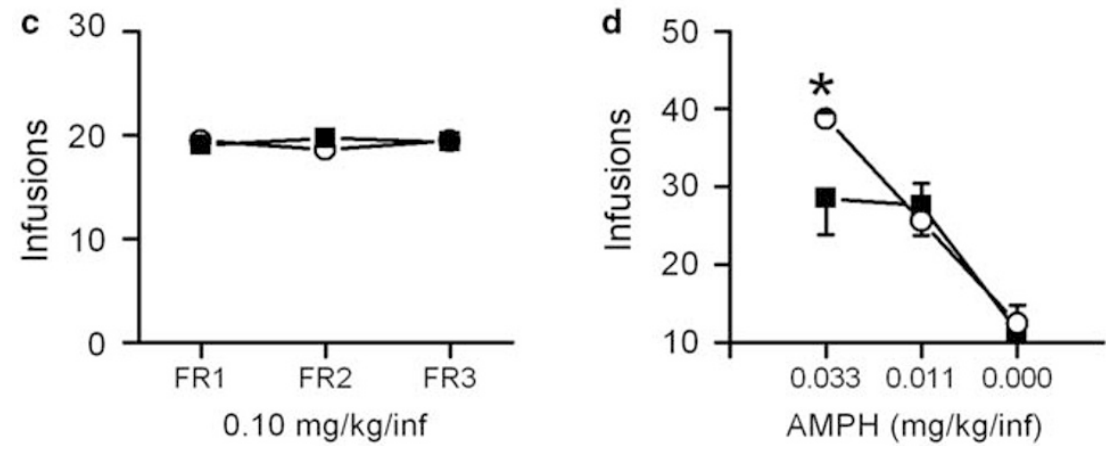

Figure 2 The effect of PSE on amphetamine self-administration in adult rats. (a, b) Amphetamine self-administration (0.1 mg/ $\mathrm{kg} / \mathrm{infusion})$ during the acquisition phase under a fixed ratio I (FR I) schedule did not differ between the control and PSE groups in the number of active responses (a; nose pokes) or infusions (b) during the first 8 days. (c) There were no differences in the number of infusions when the schedule was changed from FR I to FR 2, or FR 3 at the dose of $0.1 \mathrm{mg} / \mathrm{kg} /$ infusion of amphetamine. Data were averaged from last 2 days of each fixed ratio schedule. (d) The PSE group displayed enhanced self-administration when amphetamine dose was reduced to $0.033 \mathrm{mg} / \mathrm{kg} /$ infusion, illustrating increased amphetamine sensitivity in these animals. $* P<0.05$.

to $0.033 \mathrm{mg} / \mathrm{kg} /$ infusion while the rats were still on the FR 3 schedule, the PSE animals self-administered significantly more than the control animals (control: $28.5 \pm 4.7$ infusions; PSE: $\quad 38.7 \pm 4.6$ infusions; $t$-test, $t_{11}=2.30, \quad P<0.05$; Figure 2d; data were averaged over the last 2 days). When the amphetamine dose was further lowered to 0.011 or $0.000 \mathrm{mg} / \mathrm{kg} /$ infusion, no differences were observed between groups (Figure 2d). The results show that PSE animals exhibited significantly greater responses to the $0.033 \mathrm{mg} / \mathrm{kg}$ amphetamine dose than control animals.

\section{Prenatal Stress Exposure Led to a Persistent Reduction in VTA DA Neuron Population Activity During Adulthood}

The PSE effect on the spontaneous electrical impulse activity in VTA DA neurons in vivo was examined in adult rats. The result shows that the number of spontaneously active VTA DA neurons sampled per electrode track (population activity) was reduced $(0.53 \pm 0.10$ cells per track, $n=21$ ) by $38 \%$ in PSE animals when compared with control $\left(0.86 \pm 0.07\right.$ cells per track, $n=17$; $t$-test, $t_{36}=2.57$; $P<0.05$; Figure $3 \mathrm{a}$ ), indicating that PSE leads to a longlasting change in VTA DA neuron function during adulthood.

The firing rate and burst firing activity were randomly collected in a subset of spontaneously active VTA DA neurons. The mean firing rate of the remaining spontaneously active VTA DA neurons in PSE rats was 5.00 \pm 0.16 spikes/s $(n=137)$, which was not different from that obtained from the control rats $(5.12 \pm 0.17 ; n=110$;
Figure $3 b$ and $c)$. No differences were found in the burst firing pattern. The proportions of bursting neurons were not different between the control and PSE rats (control: 32\%; PSE: 39\%; $\chi^{2}$ test). Within the bursting neurons, the burst lengths were $4.7 \pm 0.3$ spikes/burst $(n=35)$ and $5.0 \pm 0.2$ spikes/burst $(n=50)$ in the control and PSE rats, respectively. The burst numbers were $32.1 \pm 2.9 \%(n=35)$ and $31.25 \pm 2.4 \%(n=50)$ in the control and PSE animals, respectively. Previous studies show a tight relationship between the firing rate and burst firing activity in DA neurons (Shen et al, 1994). This relationship was investigated. The correlation coefficients between firing rate and burst number or burst length from all (nonbursting and bursting) VTA DA neurons were compared between the control and PSE animals. We found no differences in these correlations ( $z$-test followed by Fisher's $r$-to- $z$ transformation; Figure $3 \mathrm{~d} 1, \mathrm{~d} 2, \mathrm{e} 1$, and e2). These results reveal that although there were fewer spontaneously active VTA DA neurons in PSE animals, the electrical impulse activity in the remaining spontaneously active neurons was normal.

\section{The Reduction in Basal VTA DA Neuron Population Activity Was Reversed by Acute Apomorphine or Psychostimulant Administration}

Apomorphine was used as the inhibitory agent (i.v.; $3-20 \mu \mathrm{g}$ ) to test the possibility of depolarization block. The results showed opposite effects of apomorphine in control and PSE rats (ANOVA with repeated measures interaction effect; $\left.\mathrm{F}_{1,7}=21, P<0.01\right)$. In control rats, apomorphine led to reduced VTA DA neuron population 

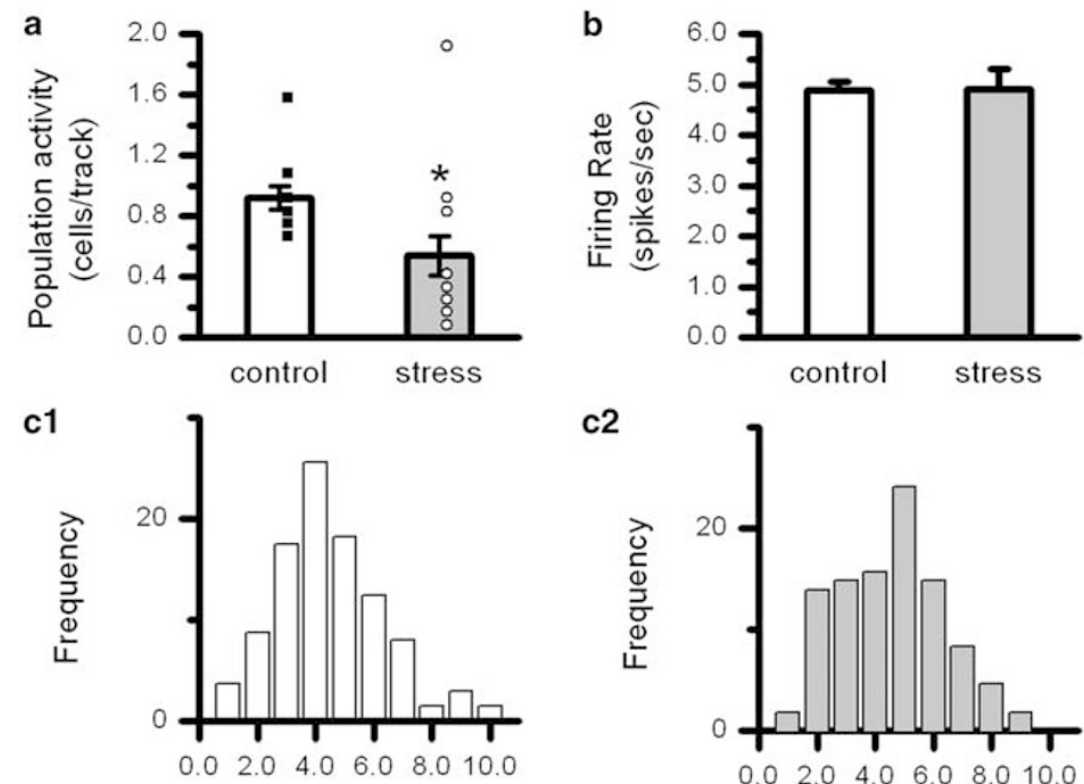

c2
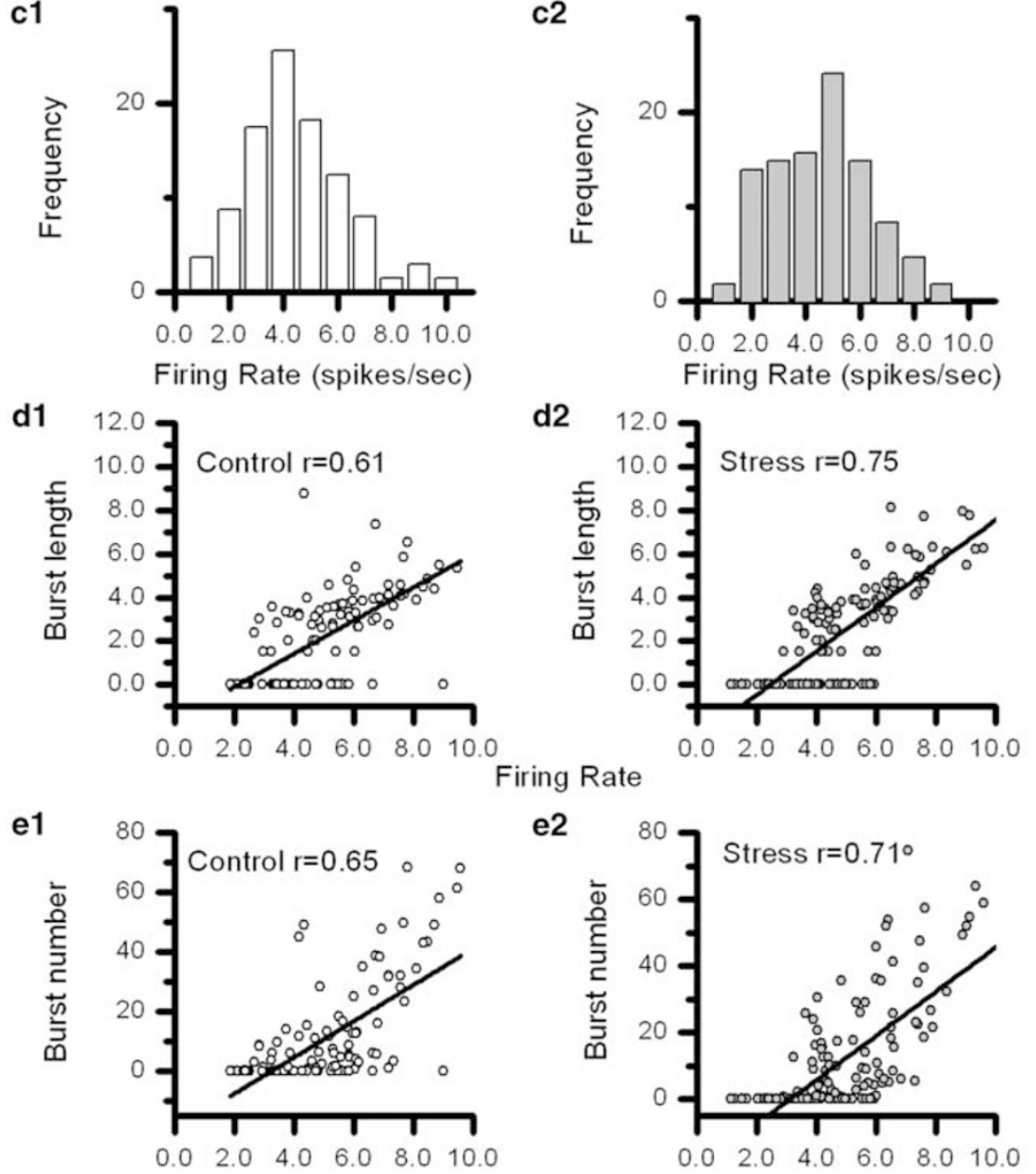

Firing Rate

Figure 3 The effects of PSE on the number of spontaneously active VTA DA neurons in adult animals. (a) The number of spontaneously active VTA DA neurons (VTA DA neuron population activity) was persistently and significantly reduced in adult animals (3-6 months old). (b) There was no change in the firing rate in the remaining spontaneously active VTA DA neurons in PSE animals. (c1, c2). The distributions of the firing rate data in control and PSE animals. $(\mathrm{dl}, \mathrm{d} 2$ ). Burst firing pattern measured by the correlation between firing rate and burst length (mean number of action potentials within a burst) did not differ between the control and PSE groups. (el, e2) Burst firing pattern measured by the correlation between firing rate and burst number (proportion of action potentials within bursts) did not differ between the control and PSE groups. Results in (c, d, and e) indicate that the remaining spontaneously active VTA DA neurons in PSE animals display normal firing activity. $* P<0.05$.

activity as expected (from $1.00 \pm 0.10$ to $0.47 \pm 0.18$ cells per track; 53\% reduction; $n=3 ; P<0.05$; Figure $4 \mathrm{a})$. In PSE rats, apomorphine reversed the reduced VTA DA neuron population activity to control levels (from $0.28 \pm 0.07$ to $0.75 \pm 0.09$ cells per track; $165 \%$ increase; $n=6 ; P<0.01$; Figure 4a). The result supports the fact that PSE-induced reduction in VTA DA neuron population activity was caused by excessive excitation to the extent of depolarization block (Bunney and Grace, 1978).

In our previous study, psychostimulants have been shown to reverse the reduced VTA DA neuron population activity due to depolarization block (Xu and Shen, 2001). Therefore, we studied the effects of acute amphetamine and cocaine administration. Amphetamine (0.3 mg/kg; i.v.) or cocaine 

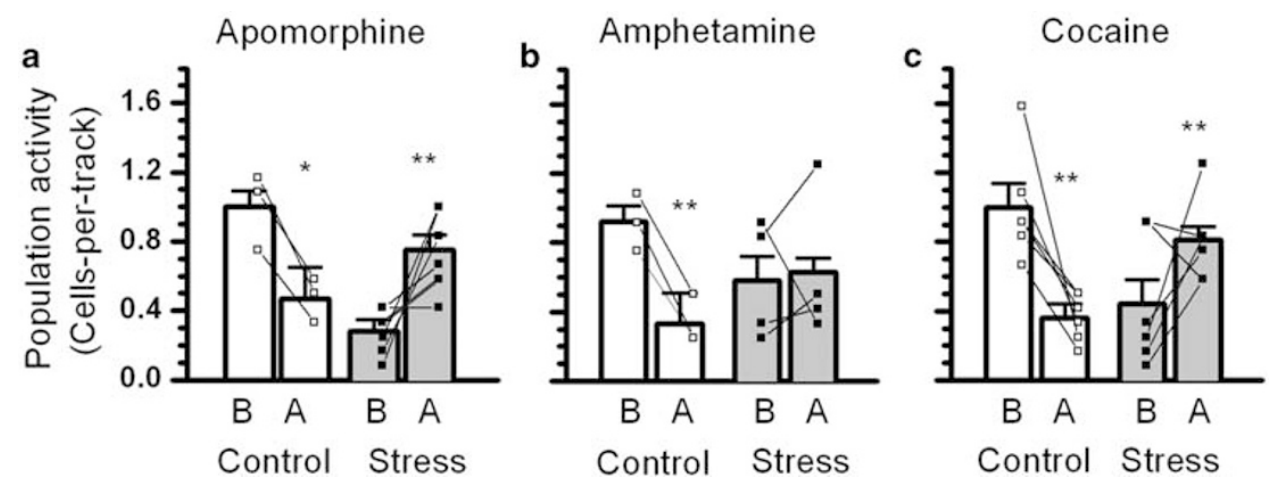

Figure 4 The reversal of PSE-induced reduction in the number of spontaneously active VTA DA neurons by inhibitory agents including psychostimulants. (a) Apomorphine $(20 \mu \mathrm{g} / \mathrm{kg})$ decreased and increased the number of spontaneously active VTA DA neurons (population activity) in control and PSE animals, respectively. Line graphs indicate the changes in individual animals. (b) Amphetamine $(0.3 \mathrm{mg} / \mathrm{kg})$ decreased VTA DA neuron population activity in control, but not in PSE animals. (c) Cocaine $(5 \mathrm{mg} / \mathrm{kg}$ ) decreased and increased VTA DA neuron population activity in control and PSE animals, respectively. Note that in (b, c), a small proportion of PSE animals displayed normal VTA DA neuron population activity before psychostimulant administration. In these animals, amphetamine or cocaine administration decreased the population activity, an effect similar to that observed in control animals. $* P<0.05$; $* * P<0.0$ I significant difference before and after acute pharmacological challenge.

(5 mg/kg, i.v.) exerted opposite effects on VTA DA neuron population activity in control and PSE rats (ANOVA with repeated measures interaction effect: $\left.\mathrm{F}_{1,17}=21.6, P<0.001\right)$. Amphetamine or cocaine administration inhibited VTA DA neuron population activity in control rats (from $0.98 \pm 0.09$ to $0.38 \pm 0.07$ cells per track; $61 \%$ reduction, $n=9$, $P<0.001$; Figure $4 \mathrm{~b}$ and $\mathrm{c}$ ), but reversed the reduced VTA DA neuron population activity in PSE rats $(0.50 \pm 0.09$ to $0.73 \pm 0.07$ cells per track; $46 \%$ increase; $n=10, P<0.01$; Figure $4 \mathrm{~b}$ and $\mathrm{c})$. Amphetamine did not $(0.58 \pm 0.14$ to $0.62 \pm 0.17$ cells per track; $n=4$; Figure $4 \mathrm{~b}$ ) but cocaine significantly reversed reduced VTA DA neuron population activity in PSE animals (from $0.44 \pm 0.14$ to $0.81 \pm 0.08$ cells per track, $P<0.05$; increased by $81.8 \%, n=6$; Figure 4 c). Interestingly, the population activity in two PSE rats was inhibited by amphetamine or cocaine administration, an effect similar to that observed in control rats. The basal population activity in these rats appeared 'normal' and not reduced as observed in other PSE animals. This observation suggests that individual differences in the PSE effect and there are VTA DA neuron population activity in a small proportion of the PSE animals was not affected. When the two 'normal' PSE rats were excluded, a significant reversal effect was observed in PSE animals with either acute amphetamine $(0.47 \pm 0.15$ to $0.72 \pm 0.20$ cells per track; $53 \%$ increase; $n=3, P<0.05$ following a significant group and amphetamine treatment interaction effect: $F_{1,4}=60$, $P<0.001)$ or cocaine $(0.35 \pm 0.14$ to $0.85 \pm 0.09$ cells per track; $143 \%$ increase; $n=5 ; P<0.05$ following a significant group and cocaine treatment interaction effect: $\mathrm{F}_{1,9}=24.42$, $P<0.001)$ treatment.

\section{DISCUSSION}

The results from the present studies show that PSE by maternal restraint leads to persistent behavioral changes during adulthood, including increased locomotor activity in a novel environment and enhanced responses to psychostimulants in the drug self-administration experiment. The amphetamine self-administration paradigm used in this study has been employed previously to investigate individual differences in increased responding to psychostimulants (Cain et al, 2008) and its association with increased addiction risk. Therefore, the results from this study are in agreement with previous animal and clinical studies demonstrating that PSE leads to increased addiction risk and associated behavioral phenotypes (Charmandari et al, 2003; Deminiere et al, 1992; Kippin et al, 2008; Moffett et al, 2007; Thomas et al, 2009).

To understand the cellular mechanisms mediating the increased addiction risk, we investigated PSE-induced changes in the spontaneous electrical impulse activity in VTA DA neurons in adult rats. The results show that the PSE paradigm that leads to increased locomotor activity to novelty and response to amphetamine also causes a persistent reduction in the spontaneous activity of VTA DA neurons recorded in adult animals. The effect is reflected in the number of VTA DA neurons displaying spontaneous activity (number of spontaneously active neurons; population activity). The firing rate and firing pattern of the remaining spontaneously active VTA DA neurons are not altered. Furthermore, the PSE-induced reduction in VTA DA neuron population activity can be reversed by acute administration of apomorphine, which reduces the population activity of VTA DA neurons in control animals. These observations-reduced DA neuron population activity, normal firing rate/pattern in the remaining spontaneously active neurons, and the reversal effect on population activity by inhibitory agents-are similar to that described after repeated antipsychotic treatment in previous studies (Grace et al, 1997). It has been proposed that the underlying mechanism for such effects is depolarization block (Grace et al, 1997). Namely, a proportion of DA neurons are overexcited, leading to depolarized membrane potential and impaired action potential generation.

The state of depolarization block and the cessation of impulse activity have been directly characterized in other brain areas utilizing the in vivo intracellular recording 
techniques (Bragin et al, 1997). However, this technique is extremely challenging for recording VTA DA neurons. Only one study has demonstrated depolarization block in several DA neurons after repeated antipsychotic treatment (Grace and Bunney, 1986). Conversely, increasing inhibitory tone by different means (eg, local administration of GABA, activation of inhibitory inputs, and apomorphine) has been shown to reverse the reduced DA neuron population activity (Choong and Shen, 2004; Shen and Chiodo, 1993). These observations provide strong, although indirect, support for the depolarization block hypothesis.

In this study, we also observe that acute psychostimulant (cocaine and amphetamine) administration reverses PSEinduced reduction in VTA DA neuron population activity. It is well known that psychostimulant administration leads to increased DA level in DA neuron target and cell body areas by blocking DA reuptake and/or increasing DA release (Kalivas and Stewart, 1991). In the cell body area, this effect leads to the activation of $\mathrm{D}_{2}$-like somatodendritic $\mathrm{DA}$ autoreceptors and the inhibition of DA neuron activity (Bunney and Grace, 1978). The inhibitory effect by acute amphetamine or cocaine administration on VTA DA neuron is indeed observed in control rats. Therefore, the reversal effect by these psychostimulants in PSE rats, similar to that of apomorphine, further supports that depolarization block is the underlying mechanism for PSE-induced reduction in VTA DA population activity. Importantly, the altered responses to psychostimulants in PSE animals could mediate increased responding to these drugs (eg, in locomotor activity and self-administration; Deminiere et al, 1992; Kippin et al, 2008; Silvagni et al, 2008; Thomas et al, 2009) and increased addiction risk in PSE rats. These behavioral characteristics are similar to those observed after repeated psychostimulant exposure (Suto et al, 2002). It is demonstrated that locomotor sensitization is mediated by a greater increase in DA level in nucleus accumbens (Kalivas and Stewart, 1991). In this study, we observe that in PSE rats, acute psychostimulants reverse the reduced VTA DA neuron population activity, an effect representing an overall increase in the impulse activity and is likely to enhance impulse-dependent DA release (Lodge and Grace, 2006). Therefore, the reversal effect could contribute to increased responding to psychostimulants in PSE rats.

The reduced VTA DA neuron population activity and its reversal by inhibitory agents including psychostimulants in PSE rats are also observed following exposure to drugs of abuse. Specifically, reduced VTA DA neuron population activity has been observed after prenatal exposure to ethanol (Choong and Shen, 2004; Shen et al, 1999; Xu and Shen, 2001) or repeated adulthood exposure to ethanol, cocaine, amphetamine, methyphenidate, or nicotine (Shen et al, 2007). In addition, the reversal effect on population activity by acute amphetamine is described after prenatal ethanol treatment (Xu and Shen, 2001). Results from both clinical and animal studies have shown that previous exposure to drugs of abuse lead to increased addiction risk (Malanga and Kosofsky, 2003; Spear and Molina, 2005). Therefore, the reduced VTA DA neuron population activity by overexcitation/depolarization block could be a common and critical cellular mechanism for increased addiction risk.

The reduced VTA DA neuron population activity in PSE rats should lead to decreased impulse-dependent DA release in the target areas (Lodge and Grace, 2006). Several studies have investigated possible changes in DA levels after PSE. Reduced DA turnover in nucleus accumbens is reported in female rats with PSE, suggesting decreased DA release (Mastorci et al, 2009). Microdialysis studies find that PSE leads to an increase in both basal and amphetaminestimulated DA levels in nucleus accumbens (Silvagni et al, 2008), but a decrease (Mokler et al, 2007) or no changes (Carboni et al., 2010) in basal level of DA in the prefrontal cortex. The cause for these differences is not clear. However, they could be influenced by various protocols that differ in timing/duration, and the nature of PSE exposure. They could also be influenced by PSE effects on impulseindependent DA release in target areas controlled by local forebrain synaptic regulatory mechanisms (Rice et al., 2011). The results from this study suggest that reduced VTA DA neuron population activity in PSE rats is due to overexcitation/depolarization block. It is conceivable that PSE at a lesser degree could result only in increased excitation in VTA DA neurons but not to the extent of depolarization block, which leads to increased impulsedependent DA release. This possibility is supported by an unusually high VTA DA neuron population activity in some PSE rats (Figure 1a). This possibility is also supported by a dichotomized pattern (either higher or lower) in VTA DA neuron population activity after repeated low-dose methyphenidate treatment (Shen and Choong, 2006). Future studies are required to examine if PSE effects on VTA DA neuron activity are different following various PSE paradigms.

The mechanisms mediating PSE-induced reduction in VTA DA neuron population activity are unclear. Existing evidence points to a possible role of increased glutamate neurotransmission via elevated stress hormones. It has been shown that elevated glucocorticoids in stressed mothers could persistently affect the HPA axis in developing fetuses (Maccari and Morley-Fletcher, 2007; Weinstock, 1997). Indeed, PSE leads to increased basal corticosterone level and blunting of HPA axis negative feedback control, resulting in a prolonged increase in glucocorticoid level after acute stress. Interestingly, stress hormones (eg, glucocorticoids and corticosterone-releasing factor) can facilitate the AMPA and NMDA receptor-mediated glutamate neurotransmission in VTA DA neurons (Daftary et al, 2009; Overton et al, 1996), suggesting that PSE-induced increase in VTA DA neuron excitation could be mediated by augmented glutamate neurotransmission. A recent study showing that acute stress increases whereas chronic stress decreases the population activity of VTA DA neurons (Velanti et al., 2012) supports that stress hormones could modulate the activity of VTA DA neurons in a dynamic way. It is tempting to speculate that the decreased population activity by chronic stress is due to overexcitation/depolarization block.

This notion is consistent with the current understanding that increased glutamate neurotransmission in VTA DA neurons is a critical cellular mechanism of addiction. For example, enhancing the expression in GluR2-lacking AMPARs in the VTA DA neurons leads to increased sensitivity to drug reward (Carlezon et al, 2000), whereas blocking glutamate receptors in the VTA during psychostimulant pre-exposure prevents enhanced psychostimulant self-administration (Suto et al, 2003). Exposure to psycho- 
stimulants, ethanol, or stress leads to augmented AMPA receptor function and greater glutamate synaptic strength in VTA DA neurons (Argilli et al, 2008; Bellone and Luscher, 2006; Borgland et al, 2004; Chen et al, 2008; Churchill et al, 1999; Fitzgerald et al, 1996; Ortiz et al, 1995; Saal et al, 2003; Stuber et al, 2008; Ungless et al, 2001; Zhang et al, 1997). Therefore, increased glutamate neurotransmission might contribute to PSE-induced overexcitation/depolarization block in VTA DA neurons and mediate the increased responding to psychostimulants and addiction risk.

In summary, the results from this study show that PSE facilitates locomotor activity to novelty/amphetamine selfadministration and reduces VTA DA neuron population activity during adulthood. The latter effect is presumably mediated by overexcitation/depolarization block. We suggest that the reversal effect on VTA DA neuron activity by psychostimulants could lead to increased DA release and mediate enhanced responding to psychostimulants and increased addiction risk in PSE rats. Furthermore, the PSEinduced reduction in VTA DA neuron population activity by overexcitation/depolarization block is consistent with current understanding that increased glutamate neurotransmission in VTA DA neurons is a critical mechanism for addiction. The PSE-induced effect on VTA DA neurons is also observed in animals with prenatal or repeated drug exposure, which are known to increase addiction risk, raising the possibility that this effect is a common mechanism for increased addiction risk and could be used as a model in developing possible pharmacological interventions to prevent addiction in high-risk individuals.

\section{ACKNOWLEDGEMENTS}

The work is supported by AA12435 (to R-YS), AA019482 (to R-YS), and MH078009 (to SH-D). We thank Dr Jerry Richards for assistance in self-administration procedures, Dr YL Shen for reading the manuscript, and Dr Amy Gancarz and Ms Michele San George for technical support in the self-administration experiment.

\section{DISCLOSURE}

The authors declare no conflict of interest.

\section{REFERENCES}

Argilli E, Sibley DR, Malenka RC, England PM, Bonci A (2008). Mechanism and time course of cocaine-induced long-term potentiation in the ventral tegmental area. J Neurosci 28: 9092-9100.

Bellone C, Luscher C (2006). Cocaine triggered AMPA receptor redistribution is reversed in vivo by mGluR-dependent longterm depression. Nat Neurosci 9: 636-641.

Borgland SL, Malenka RC, Bonci A (2004). Acute and chronic cocaine-induced potentiation of synaptic strength in the ventral tegmental area: electrophysiological and behavioral correlates in individual rats. J Neurosci 24: 7482-7490.

Bragin A, Penttonen M, Buzsaki G (1997). Termination of epileptic afterdischarge in the hippocampus. J Neurosci 17: 2567-2579.

Brischoux F, Chakraborty S, Brierley D, Ugless M (2009). Phasic excitation of dopamine neurons in ventral VTA by noxious stimuli. Proc Natl Acad Sci USA 106: 4894-4899.
Bunney BS, Grace AA (1978). Acute and chronic haloperidol treatment: comparison of effects on nigral dopaminergic cell activity. Life Sci 23: 1715-1727.

Cain ME, Denehy ED, Bardo MT (2008). Individual differences in amphetamine self-administration: the role of the central nucleus of the amygdala. Neuropsychopharmacology 33: 1149-1161.

Carboni E, Barros VG, Ibba M, Silvagni A, Mura C, Antonelli MC (2010). Prenatal restraint stress: an in vivo microdialysis study on catecholamine release in the rat prefrontal cortex. Neuroscience 168: 156-166.

Carlezon WA Jr, Haile CN, Coppersmith R, Hayashi Y, Malinow R, Neve RL et al (2000). Distinct sites of opiate reward and aversion within the midbrain identified using a herpes simplex virus vector expressing GluR1. J Neurosci 20: RC62.

Charmandari E, Kino T, Souvatzoglou E, Chrousos GP (2003). Pediatric stress: hormonal mediators and human development. Horm Res 59: 161-179.

Chen BT, Bowers MS, Martin M, Hopf FW, Guillory AM, Carelli RM et al (2008). Cocaine but not natural reward selfadministration nor passive cocaine infusion produces persistent LTP in the VTA. Neuron 59: 288-297.

Choong K, Shen R (2004). Prenatal ethanol exposure alters the postnatal development of the spontaneous electrical activity of dopamine neurons in the ventral tegmental area. Neuroscience 126: 1083-1091.

Churchill L, Swanson CJ, Urbina M, Kalivas PW (1999). Repeated cocaine alters glutamate receptor subunit levels in the nucleus accumbens and ventral tegmental area of rats that develop behavioral sensitization. J Neurochem 72: 2397-2403.

Daftary SS, Panksepp J, Dong Y, Saal DB (2009). Stress-induced, glucocorticoid-dependent strengthening of glutamatergic synaptic transmission in midbrain dopamine neurons. Neurosci Lett 452: 273-276.

Deminiere JM, Piazza PV, Guegan G, Abrous N, Maccari S, Le Moal $M$ et al (1992). Increased locomotor response to novelty and propensity to intravenous amphetamine selfadministration in adult offspring of stressed mothers. Brain Res 586: 135-139.

Everitt BJ, Belin D, Economidou D, Pelloux Y, Dalley JW, Robbins TW (2008). Review. Neural mechanisms underlying the vulnerability to develop compulsive drug-seeking habits and addiction. Philos Trans R Soc Lond B Biol Sci 363: 3125-3135.

Fitzgerald LW, Ortiz J, Hamedani AG, Nestler EJ (1996). Drugs of abuse and stress increase the expression of GluR1 and NMDAR1 glutamate receptor subunits in the rat ventral tegmental area: common adaptations among cross-sensitizing agents. J Neurosci 16: $274-282$.

Grace AA, Bunney BS (1983). Intracellular and extracellular electrophysiology of nigral dopaminergic neurons-1. Identification and characterization. Neuroscience 10: 301-315.

Grace AA, Bunney BS (1984). The control of firing pattern in nigral dopamine neurons: burst firing. J Neurosci 4: 2877-2890.

Grace AA, Bunney BS (1986). Induction of depolarization block in midbrain dopamine neurons by repeated administration of haloperidol: analysis using in vivo intracellular recording. J Pharmacol Exp Ther 238: 1092-1100.

Grace AA, Bunney BS, Moore H, Todd CL (1997). Dopamine-cell depolarization block as a model for the therapeutic actions of antipsychotic drugs. Trends Neurosci 20: 31-37.

Kalivas PW, Stewart J (1991). Dopamine transmission in the initiation and expression of drug- and stress-induced sensitization of motor activity. Brain Res Brain Res Rev 16: 223-244.

Kippin TE, Szumlinski KK, Kapasova Z, Rezner B, See RE (2008). Prenatal stress enhances responsiveness to cocaine. Neuropsychopharmacology 33: 769-782.

Koob GF, Le Moal M (1997). Drug abuse: hedonic homeostatic dysregulation. Science 278: 52-58. 
Lesage J, Del-Favero F, Leonhardt M, Louvart H, Maccari S, Vieau D et al (2004). Prenatal stress induces intrauterine growth restriction and programmes glucose intolerance and feeding behaviour disturbances in the aged rat. J Endocrinol 181: 291-296.

Lodge DJ, Grace AA (2006). The hippocampus modulates dopamine neuron responsivity by regulating the intensity of phasic neuron activation. Neuropsychopharmacology 31: 1356-1361.

Maccari S, Darnaudery M, Morley-Fletcher S, Zuena AR, Cinque C, Van Reeth O (2003). Prenatal stress and long-term consequences: implications of glucocorticoid hormones. Neurosci Biobehav Rev 27: 119-127.

Maccari S, Morley-Fletcher S (2007). Effects of prenatal restraint stress on the hypothalamus-pituitary-adrenal axis and related behavioural and neurobiological alterations. Psychoneuroendocrinology 32(Suppl 1): S10-S15.

Malanga CJ, Kosofsky BE (2003). Does drug abuse beget drug abuse? Behavioral analysis of addiction liability in animal models of prenatal drug exposure. Brain Res Dev Brain Res 147: 47-57.

Marinelli M, Piazza PV (2002). Interaction between glucocorticoid hormones, stress and psychostimulant drugs. Eur J Neurosci 16: 387-394.

Mastorci F, Vicentini M, Viltart O, Manghi M, Graiani G, Quaini F et al (2009). Long-term effects of prenatal stress: changes in adult cardiovascular regulation and sensitivity to stress. Neurosci Biobehav Rev 33: 191-203.

Moffett MC, Vicentic A, Kozel M, Plotsky P, Francis DD, Kuhar MJ (2007). Maternal separation alters drug intake patterns in adulthood in rats. Biochem Pharmacol 73: 321-330.

Mokler DJ, Torres OI, Galler JR, Morgane PJ (2007). Stress-induced changes in extracellular dopamine and serotonin in the medial prefrontal cortex and dorsal hippocampus of prenatally malnourished rats. Brain Res 1148: 226-233.

Ortiz J, Fitzgerald LW, Charlton M, Lane S, Trevisan L, Guitart X et al (1995). Biochemical actions of chronic ethanol exposure in the mesolimbic dopamine system. Synapse 21: 289-298.

Overton PG, Tong ZY, Brain PF, Clark D (1996). Preferential occupation of mineralocorticoid receptors by corticosterone enhances glutamate-induced burst firing in rat midbrain dopaminergic neurons. Brain Res 737: 146-154.

Piazza PV, Deminiere JM, Le Moal M, Simon H (1989). Factors that predict individual vulnerability to amphetamine self-administration. Science 245: 1511-1513.

Rice ME, Patel JC, Cragg SJ (2011). Dopamine release in the basal ganglia. Neuroscience 198: 112-137.

Saal D, Dong Y, Bonci A, Malenka RC (2003). Drugs of abuse and stress trigger a common synaptic adaptation in dopamine neurons. Neuron 37: 577-582.

Shaham Y, Shalev U, Lu L, De Wit H, Stewart J (2003). The reinstatement model of drug relapse: history, methodology and major findings. Psychopharmacology (Berl) 168: 3-20.

Shen RY, Altar CA, Chiodo LA (1994). Brain-derived neurotrophic factor increases the electrical activity of pars compacta dopamine neurons in vivo. Proc Natl Acad Sci USA 91: 8920-8924.

Shen RY, Chiodo LA (1993). Acute withdrawal after repeated ethanol treatment reduces the number of spontaneously active dopaminergic neurons in the ventral tegmental area. Brain Res 622: 289-293.
Shen RY, Choong KC (2006). Different adaptations in ventral tegmental area dopamine neurons in control and ethanol exposed rats after methylphenidate treatment. Biol Psychiatry 59: 635-642.

Shen RY, Choong KC, Thompson AC (2007). Long-term reduction in ventral tegmental area dopamine neuron population activity following repeated stimulant or ethanol treatment. Biol Psychiatry 61: 93-100.

Shen RY, Hannigan JH, Kapatos G (1999). Prenatal ethanol reduces the activity of adult midbrain dopamine neurons. Alcohol Clin Exp Res 23: 1801-1807.

Silvagni A, Barros VG, Mura C, Antonelli MC, Carboni E (2008). Prenatal restraint stress differentially modifies basal and stimulated dopamine and noradrenaline release in the nucleus accumbens shell: an 'in vivo' microdialysis study in adolescent and young adult rats. Eur J Neurosci 28: 744-758.

Spear NE, Molina JC (2005). Fetal or infantile exposure to ethanol promotes ethanol ingestion in adolescence and adulthood: a theoretical review. Alcohol Clin Exp Res 29: 909-929.

Stuber GD, Hopf FW, Hahn J, Cho SL, Guillory A, Bonci A (2008). Voluntary ethanol intake enhances excitatory synaptic strength in the ventral tegmental area. Alcohol Clin Exp Res 32: $1714-1720$

Suto N, Austin JD, Tanabe LM, Kramer MK, Wright DA, Vezina P (2002). Previous exposure to VTA amphetamine enhances cocaine self-administration under a progressive ratio schedule in a D1 dopamine receptor dependent manner. Neuropsychopharmacology 27: 970-979.

Suto N, Tanabe LM, Austin JD, Creekmore E, Vezina P (2003). Previous exposure to VTA amphetamine enhances cocaine selfadministration under a progressive ratio schedule in an NMDA, AMPA/kainate, and metabotropic glutamate receptor-dependent manner. Neuropsychopharmacology 28: 629-639.

Thomas MB, Hu M, Lee TM, Bhatnagar S, Becker JB (2009). Sexspecific susceptibility to cocaine in rats with a history of prenatal stress. Physiol Behav 97: 270-277.

Ungless MA, Whistler JL, Malenka RC, Bonci A (2001). Single cocaine exposure in vivo induces long-term potentiation in dopamine neurons. Nature 411: 583-587.

Velanti O, Gill KM, Grace AA (2012). Different stressors produce excitation or inhibition of mesolimbic dopamine neuron activity: response alteration bystress pre-exposure. Eur J Neurosci 35: 1312-1321.

White FJ, Hu XT, Zhang XF, Wolf ME (1995). Repeated administration of cocaine or amphetamine alters neuronal responses to glutamate in the mesoaccumbens dopamine system. J Pharmacol Exp Ther 273: 445-454.

Weinstock M (1997). Does prenatal stress impair coping and regulation of hypothalamic-pituitary-adrenal axis? Neurosci Biobehav Rev 21: 1-10.

Xu C, Shen RY (2001). Amphetamine normalizes the electrical activity of dopamine neurons in the ventral tegmental area following prenatal ethanol exposure. J Pharmacol Exp Ther 297: $746-752$.

Zhang XF, Hu XT, White FJ, Wolf ME (1997). Increased responsiveness of ventral tegmental area dopamine neurons to glutamate after repeated administration of cocaine or amphetamine is transient and selectively involves AMPA receptors. J Pharmacol Exp Ther 281: 699-706. 